\title{
An Approach to Evaluate the General Performance of Stand-Alone Wind/Photovoltaic Generating Systems
}

\author{
M. Hashem Nehrir, Senior Member, IEEE, Brock J. LaMeres, Member, IEEE, \\ Giri Venkataramanan, Senior Member, IEEE, Victor Gerez, Senior Member, IEEE, and L. A. Alvarado
}

\begin{abstract}
This paper reports the development of a computer approach for evaluating the general performance of stand-alone wind/photovoltaic generating systems. Simple models for different system components are developed, integrated, and used to predict the behavior of generating systems based on available wind/solar and load data. The model is useful for evaluating the performance of stand-alone generating systems and gaining a better insight in the component sizes needed before they are built. Simulation results are presented for performance evaluation of a stand-alone generating system that has been previously designed to supply the average power demand of a typical residential house [1].

An electric water heater model is used as a dump load, and the excess available wind/solar-generated power is used to heat the water. The heated water is used as the inlet water to the main house water heater, which is assumed to be nonelectric. It is shown that this strategy can be effective in reducing the amount of fuel used by the main residential water heater.
\end{abstract}

Index Terms-Computer modeling, electric water heater dump load, wind/PV generation.

\section{INTRODUCTION}

$\mathbf{T}$ HE LIMITED reserves of fossil fuels and global environmental concerns over their use for electric power generation have increased the interest in the utilization of renewable energy resources. In particular, rapid advances in wind-turbine generator and photovoltaic technologies have brought opportunities for the utilization of wind and solar resources for electric power generation world-wide. Moreover, the economic aspects of these technologies are now sufficiently promising to also justify their use in small-scale stand-alone applications for residential/ranch use; several design scenarios have been proposed for the design of wind/solar power systems for stand-alone applications, i.e. [1]-[3].

This paper describes the development of a computer-based approach for evaluating the general performance of stand alone hybrid wind-PV generating systems. Hourly average wind speed/solar radiation data from the site for the generating unit and the anticipated load data are used to predict the general

Manuscript received June 22, 1999. This work was supported by the Montanans on a New Track for Science (MONTS) and DOE/EPSCoR programs at Montana State University.

M. H. Nehrir, G. Venkataramanan, and V. Gerez are with the Electrical and Computer Engineering Department, Montana State University, Bozeman, MT 59717.

B. J. LaMeres was with the Electrical and Computer Engineering Department Montana State University, Bozeman, MT 59717. He is now with the Hewlett Packard Company, Colorado Springs, CO.

L. A. Alvarado was with the Electrical and Computer Engineering Department, Montana State University, Bozeman, MT 59717. He is now with QUALCOMM Inc., Boulder, CO.

Publisher Item Identifier S 0885-8969(00)11004-6. performance of the generating system. Such performance evaluation can be useful in estimating the component sizes needed for generating systems to supply power to loads reliably. It is also helpful in performing a detailed economical analysis (cost benefit study) for the generating unit.

Of particular interest is the model used for dump load. The excess wind/solar-generated power, when available, is used to heat water in an electric water heater. This heated water can be used for any purposes such as animal drinking water (in the winter). In this study the pre-heated water is used as inlet water to the main house water heater, which is assumed to be nonelectric. It is found that this strategy can be an effective way of reducing the amount of fuel needed to heat water in the main house water heater.

Simulation studies were carried out using MATLAB/SIMULINK software package. A time step of one hour was used in the simulation studies since the general (not detailed minute-by-minute) performance of the generating system was of interest.

In the remainder of this paper the system configuration and models used for different system components will be presented. Simulation results will be given for performance evaluation of a stand-alone hybrid wind-PV generating unit for a residential house assumed to be located in a remote area in south-central Montana for which component sizing has been done previously [1]. Finally, a discussion of results obtained and methods to enhance the performance of the proposed model will be presented and conclusions drawn.

\section{SYSTEM CONFIGURATION}

The block diagram for a typical stand-alone wind-PV generating system is shown in Fig. 1. The system consists of wind turbine generator(s), PV panels, storage batteries, backup generator, and dump load. Provisions for the availability of both AC and DC buses are made using electronic converters. The generating system components can be selected, for the load to be supplied, based on a component sizing strategy [1]-[3]. However, this is not a requirement, and the model can be used to estimate the generation and storage battery sizes needed for a particular application.

Storage batteries are charged when wind/solar generation exceeds the demand until a specified upper limit for the battery voltage is reached. At this point the excess available power is diverted to the dump load, which in this study is assumed to be an electric water heater. The power absorbed by an electric water heater can be made variable by controlling the voltage applied to the water heater [4], [5]. Batteries will discharge, supplying 


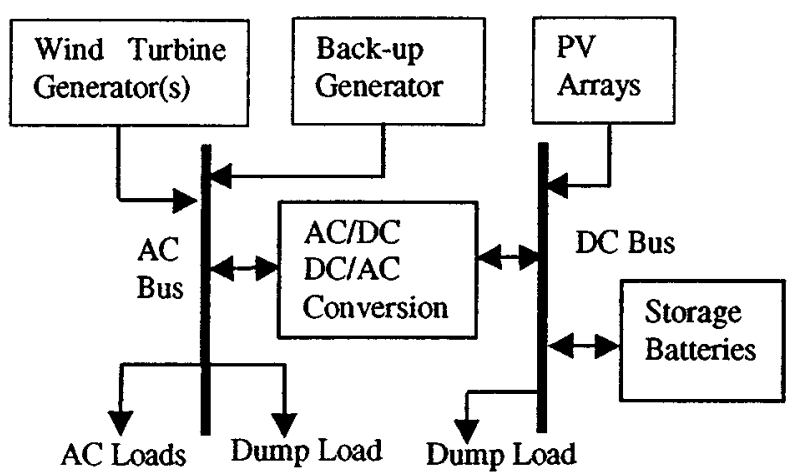

Fig. 1. Stand-alone wind-PV generating system configuration.

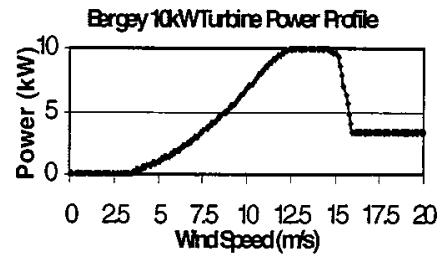

Fig. 2. Power curve of a 10-kW Bergey wind generator.

power to the load when demand exceeds generation. They will continue discharging until a specified lower limit for the battery voltage is reached. At that, point the batteries will stop supplying power to the load and the back-up generator will come on to supply the required power to the load.

\section{COMPONENT MODELING}

Since in this study the general (hourly) performance of the generating system is of interest, simple steady-state models for the wind turbine generator (WTG), PV arrays, and the back-up generator are used. A battery model reported in [6] is used to predict the general charging/discharging characteristics of the storage batteries. A computer model is also used for the electric water heater dump load to predict the variation of water temperature with time [8].

\section{A. Wind Turbine and PV Array Models}

A simple lookup table is used to convert the available wind speed to electric power using the WTG's power curve provided by the manufacturer. In this study the power curve of a $10-\mathrm{kW}$ Bergey WTG, shown in Fig. 2, is used. The available insolation data $\left(\mathrm{W} / \mathrm{m}^{2}\right)$ and the total number of PV panels used, together with the panel efficiency, provide the total available PVgenerated electric power.

\section{B. Back-Up Generator Model}

The back-up generator is to provide the required power $\left(|\Delta P|=P_{\text {wind }}+P_{\text {solar }}-P_{\text {demand }}\right)$ to the load when $\Delta P$ is negative and the storage batteries cannot provide the required power. The back-up generator is modeled as a variable power

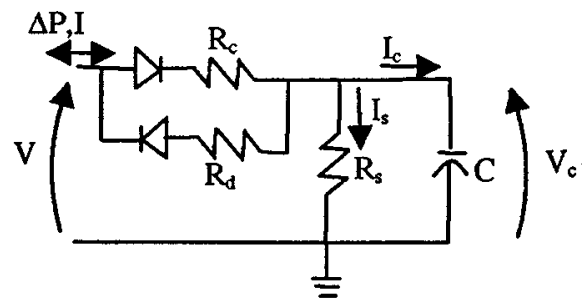

$\Delta \mathrm{P}, \mathrm{I}=$ Input/output power, current

$\mathrm{V}_{\mathrm{c}}, \mathrm{V}=$ Battery nominal, output voltage

$R_{c}, R_{d}, R_{s}=$ Charge, Discharge, Self-Discharge Resistance

$\mathrm{C}=$ Battery capacitance

Fig. 3. Battery equivalent circuit [6].

source $\left(P_{b g}\right)$ with a fixed terminal voltage. The value of $P_{b g}$ at any time $(t)$ is given by (1).

$$
\begin{aligned}
& P_{b g}=0 \text { when } \Delta P \geq 0, \\
& P_{b g}=0 \text { when } \Delta P<0 \text { and } V_{\text {battery }}>85 \% \text { of rated, } \\
& P_{b g}=|\Delta P| \text { when } \Delta P<0 \text { and } V_{\text {battery }} \leq 85 \% \text { of rated }
\end{aligned}
$$

\section{Storage Battery Model}

A model for the storage battery is needed to predict the rate at which the battery is charged (discharged) when the generated power is more (less) than demand. It is assumed that lead acid batteries are used. The equivalent circuit used for these batteries, taken from [6], is shown in Fig. 3. The input power to this equivalent circuit is the charging/discharging power $(\Delta P)$. Power will flow into the batteries when the generated power exceeds demand $(\Delta P>0)$ and will flow out of the batteries when $\Delta P<0$. The output signal is the battery voltage which will vary as a function of power flow into or out of the battery. Protection against overvoltage and undervoltage is provided to prevent battery overcharge and overdischarge. A minimum voltage is considered as the end of discharge (EOD) for the batteries to ensure their maximum life time [7]. In this study a nominal, battery voltage of $24 \mathrm{~V}$ is used, with $V_{\max }=26$ and $V_{\min }=20.4 \mathrm{~V}$ ( $85 \%$ of the nominal voltage). Therefore, batteries will stop charging when the voltage reaches $26 \mathrm{~V}$ and will stop supplying power to the load when the voltage falls to $20.4 \mathrm{~V}$. Series/parallel combination of the batteries may be needed to obtain the desired nominal output voltage. The mathematical development for obtaining the battery voltage as a function of the power flow into or out of the battery and the model parameter values used are given in Appendix A.

\section{Dump Load Model}

The dump load is a resistive load $(R)$ which consumes any excess wind/solar-generated power $(\Delta P)$. Since $\Delta P$ varies with time, the dump load can be modeled with a variable resistor having a fixed voltage across it, or as a fixed resistor having a variable voltage. In either case, the variable power is $\Delta P=$ $V^{2} / R$ or $V=(\Delta P \cdot R)^{1 / 2}$. In this study a conventional residential electric water heater (with a $220-\mathrm{V}, 4.5-\mathrm{kW}$ heating element) is used as dump load, which is assumed to be the house auxiliary water heater. It will use any excess available power $(\Delta P)$ to heat the water. The power supplied to this water heater is varied 
by varying its voltage using an electronic voltage controller [4], [5]. The water heated by this water heater can be used in any way the user wishes. In this study, it is assumed that the heated water is used as the incoming water to the main house water heater, which is assumed to be nonelectric. This configuration can be beneficial to save on any type of fuel (such as propane) that the main house water heater uses. Because the inlet water to this water heater is pre-heated by the dump load electric water heater, less fuel would be needed to heat the water to the desired temperature. The economic study of the proposed electric water beater dump load is out of the scope of this paper and will be carried out in the future.

The dynamics of the water heater can be expressed by the variation of hot water temperature as a function of time and can be expressed as follows [8], [9].

$$
\begin{aligned}
T_{h}(t)= & {\left[T_{h}(\tau) \cdot e^{-\left(1 / R^{\prime} C\right)(t-\tau)}\right] } \\
& +\left[G R^{\prime} T_{\text {out }}+B(t) \cdot R^{\prime} \cdot T_{\text {in }}+Q(t) R^{\prime}\right] \\
& \cdot\left[1-e^{-\left(1 / R^{\prime} C\right)(t-\tau)}\right]
\end{aligned}
$$

The parameters in equation (2) are:

$T_{h}(t) \quad=$ Mean tank water temperature at time $t\left({ }^{\circ} \mathrm{F}\right)$,

$T_{\text {out }}=$ Ambient temperature of the area surrounding the water heater tank $\left({ }^{\circ} \mathrm{F}\right)$,

$T_{\text {in }} \quad=$ Incoming cold water temperature $\left({ }^{\circ} \mathrm{F}\right)$,

$\tau \quad=$ Initial time (sec.)

$Q \quad=$ Water heater input power (BTU/hr),

$R^{\prime} \quad=1 /(G+B(t))$,

$G \quad=(S A)(1 / R)$

$B(t) \quad=\rho W_{D}(t)\left(C_{p}\right)$

$\rho \quad=$ Specific mass of water ( $8.3 \mathrm{lbs} /$ gallon of water),

$W_{D}(t) \quad=$ Hot water demand $(\mathrm{gal} / \mathrm{hr})$,

$C_{p} \quad=$ Specific heat of water $\left[\mathrm{BTU} /\left({ }^{\circ} \mathrm{F}-\mathrm{lb}\right)\right]$,

$S A \quad=$ Water heater tank surface area,

$R=$ Tank insulation thermal resistance (hour $\mathrm{ft}^{2}$ $\left.{ }^{\circ} \mathrm{F} / \mathrm{BTU}\right)$,

$C=$ Tank equivalent thermal mass $\left(\mathrm{BTU} /{ }^{\circ} \mathrm{F}\right)$ given by (gallons) $\cdot \rho \cdot C_{p}$.

Using the above equation, the temperature of hot water in the auxiliary electric water heater tank can be predicted as a function of the excess available wind/solar-generated power $(\Delta P)$, which is to be dumped to the water heater.

\section{Simulation Results}

The component models presented above were integrated to evaluate the general hourly performance of a stand-alone Wind/PV generating system that was designed to supply the electrical power requirement of an average house assumed to be located in a remote area in south-central Montana [1]. The hourly average wind and solar power generation, average power demand, and the $\Delta P$ profiles for the house are given in Fig. 4. The component ratings used for the generating system, based on the design procedure given in [1], are listed in Table I.

Note that in Fig. $4 \Delta P$ is positive when the sum of wind and solar-generated power exceeds power demand, and it is negative otherwise. The battery voltage and power profiles are shown in
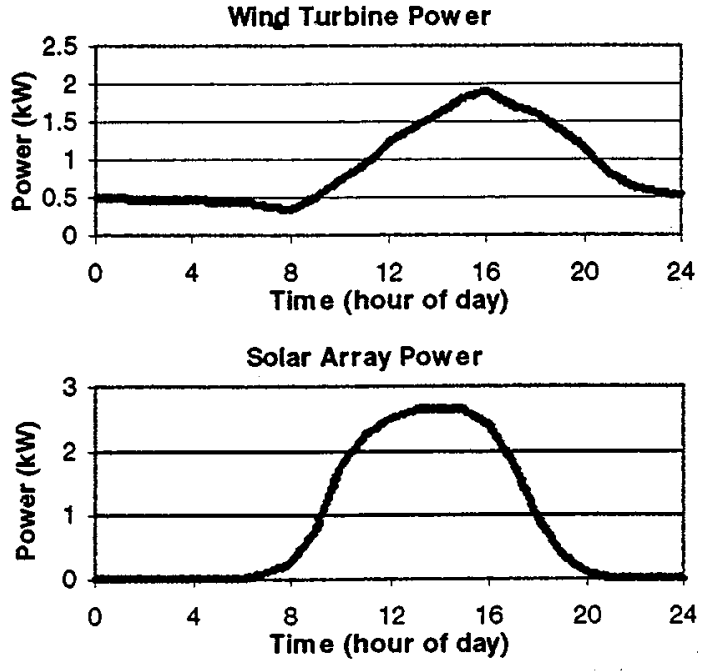

House Demand w/out Hot Water

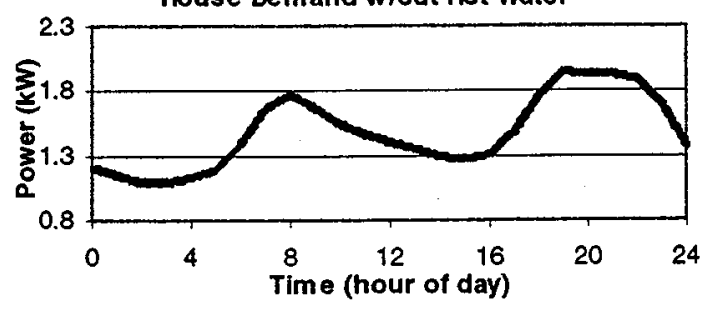

Delta - $\mathbf{P}$

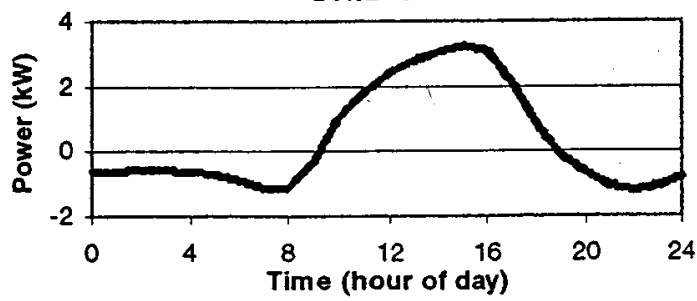

Fig. 4. Generation, power demand, and $\Delta P$ profiles.

TABLE I

COMPONENT Ratings ChOSEn for the EXAMPLE STAND-Alone WIND/PV SYSTEM [1]

\begin{tabular}{l|l|l}
\hline Component & Rating & Number \\
$\begin{array}{l}\text { Wind Turbine } \\
\text { Generator }\end{array}$ & $10 \mathrm{~kW}$ & 1 \\
\hline Solar Panel & $53 \mathrm{~W}$ & 72 \\
\hline $\begin{array}{l}\text { Back-up } \\
\text { Generator }\end{array}$ & $3.2 \mathrm{~kW}$ & 1 \\
$\begin{array}{l}\text { Deep Cycle } \\
\text { Battery }\end{array}$ & $2.1 \mathrm{kWh}$ (total) & \\
\hline
\end{tabular}

Fig. 5. Batteries supply power to the load when $\Delta P$ is negative and the battery voltage is above $20.4 \mathrm{~V}$.

They are charged when $\Delta P>0$ and the battery voltage is less than $26 \mathrm{~V}$. The charge and discharge rate of the batteries depend on $\Delta P$ and the battery equivalent circuit parameter values used.

Fig. 6 shows the power supplied to the load by the back-up generator. This unit comes on and supplies the required power 

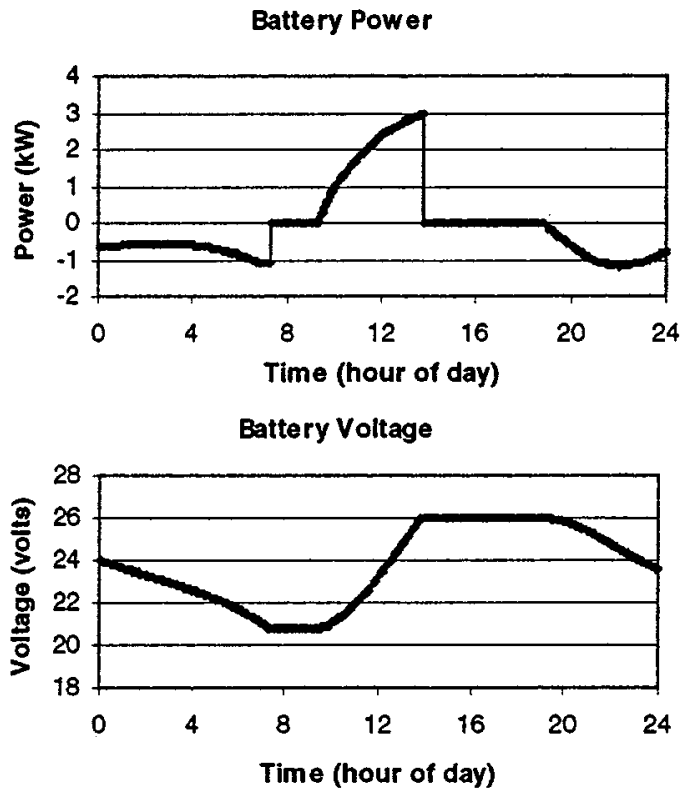

Fig. 5. Battery voltage and power profiles.

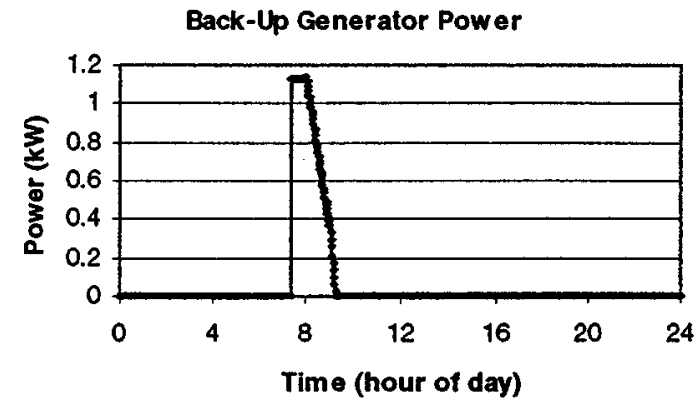

Fig. 6. Back-up generator power profile.

to the load when $\Delta P<0$ if the battery voltage falls to $20.4 \mathrm{~V}$. Note from Fig. 5 that the battery discharges in the early morning hours (because of lack of enough wind and solar generation) until about 8:00 hours, where the battery voltage falls to its minimum level of $20.4 \mathrm{~V}$. At that time the batteries stop supplying power to the load and the back-up generator comes on to supply the required power $\left(P_{b g}=P_{\text {demand }}-P_{g e n}\right)$ to the load. At 10:00 hours, generation exceeds the demand; the back-up generator is turned off, and the batteries begin and continue charging until 14:00 hours when the battery voltage reaches its upper limit of $26 \mathrm{~V}$ and stops charging. After that time, the excess wind/solar-generated power is supplied to a 50-gallon electric water heater used as a dump load. Power supplied to the water heater, as a function of hour of day, is shown in Fig. 7. At 19:00 hours $\Delta P$ goes negative (Fig. 5), and the power supplied to the water heater goes to zero. At this time the batteries start discharging to supply the required power to the load.

Fig. 8 shows the temperature profile of the water in the dump load water heater tank for 72 hours. It is assumed that the incoming cold water to the dump load water heater is at $40^{\circ} \mathrm{F}$, and its output (hot water) pipe is connected to the main water heater cold water (input) pipe. Simulation has been performed for 72 hours to make sure water temperature comes

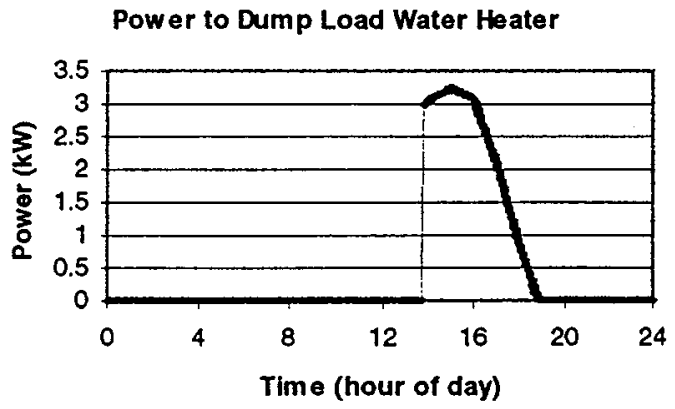

Fig. 7. Power supplied to the dump load water heater.

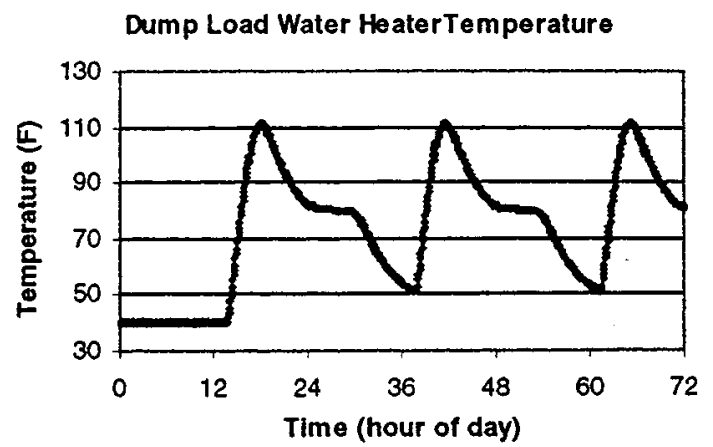

Fig. 8. Temperature profile of water in the dump load water heater tank.

to steady-state. Initially, the temperature of the water in the water heater tank is the same as that of the incoming cold water. Between 14:00 and 19:00 hours power is supplied to the water heater. Water temperature starts rising at 14:00 hours. However, at 18:00 hours it begins to fall because the power supplied to the water heater has decreased, and also because of hot water usage in the house hold. Daily average hot water usage of an average house, taken from [10], was assumed to be taken out of the main house water heater and therefore from the dump load water heater.

The rate at which hot water temperature in the dump load water heater rises or falls depends on the water heater model parameters defined immediately below equation (2).

The water heater parameter values used in the current study are given in Appendix B.

In order to see the effectiveness of using a dump load water heater to pre-heat the water flowing into the main house water heater, the on-off performance characteristic of the main house water heater was studied under two scenarios. In the first scenario, the dump load water heater is bypassed, and cold water $\left(40^{\circ} \mathrm{F}\right)$ flows directly into the main house water heater. In the second scenario, cold water is assumed to be pre-heated in the dump-load water heater using the excess wind/solar power and then flow into the main water heater. In both scenarios, the main water heater is assumed to be thermostat controlled and nonelectric with a thermostat set-point of $130^{\circ} \mathrm{F}$ and deadband of $10^{\circ} \mathrm{F}$. The main water heater on-off performance for the above two scenarios are shown in Fig. 9. It is clear from this figure that the operating time of the main water heater is significantly less when its incoming water is pre-heated by the dump load auxiliary water heater. This lower operating time translates into savings in the fuel the main water heater uses to heat water. In this 


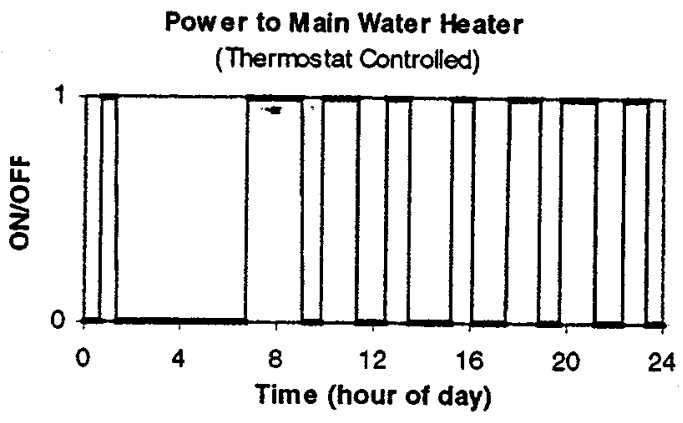

(a)

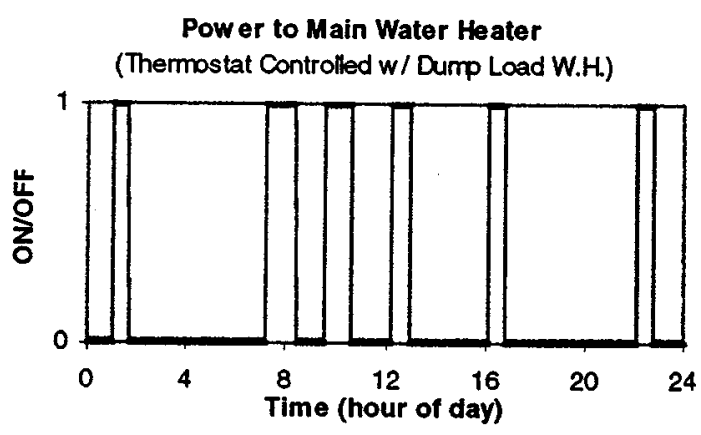

(b)

Fig. 9. On-off performance of the main house water heater under two scenarios. (a) Without using water from the dump load water heater. (b) Using water from the dump load water heater.

simulation study, the sampling interval is set at one hour to observe the general performance characteristics of the main water heater over the entire day. In practice, water heater on-time (offtime) is in the order of minutes and depends on the input power to the water heater and the rate of hot water usage.

\section{Discussion OF RESUlts}

This paper presented an approach for evaluating the general performance of stand-alone wind/PV generating systems. A discussion of the results obtained and limitations of the approach are presented here so that the users who wish to apply it are familiar with, and therefore apply it for purposes intended; or modify it properly to suit their needs.

1) Hourly average wind speed, solar radiation and power demand, and a time step of one hour were used in the simulation study since a study of the general hourly (not minute-by-minute or second-by-second) performance of the generating system was of interest. By selecting a time a step of one hour, we are assuming constant wind speed and solar radiation during each hour. This assumption does not have considerable effect on the general hourly response of the generating system since hourly average data were used. However, one should have in mind that both wind and solar radiation are highly intermittent, and therefore the variability in the power generated by the wind/PV generating systems is dependent on the stochastic nature of wind and solar radiation. Therefore, assuming constant wind speed and solar radiation within an hour will not be entirely accurate if a more detailed response of the wind/PV generating system is of interest.
In that case, an approach can be used to take the variability of the wind speed and solar radiation into account by considering the stochastic distribution of wind and solar radiation by using proper distribution curves, such as the Weibull distribution for wind [11].

Using such distribution curves, the power generation within each hour can be corrected accordingly. In one study the authors used both hourly and 15-minute wind data for the site studied in this paper and showed that taking the effect of wind variability into account did not have considerable effect on the general hourly wind power generation over a period of time [12]. If more detailed response of the system is of interest, a smaller simulation time step (15 minutes or one minute) can be used if 15-minute or one-minute wind/solar radiation (and demand) data are available. In such case, a dynamic model should be used for the wind turbine generator, and more be even more justified in the future considering the falling detailed performance of the battery and dump load model (in prices of the wind/PV generating system components and this case electric water heater) will be obtained.

2) Estimated values of battery resistance parameters (charge, discharge, and self-discharge resistances) were used in this study to show the charging/discharging characteristics of the batteries of the generating system. These parameter values were chosen based on the battery characteristic curves provided in [7]. In an actual situation, however, the battery parameters vary with the operating temperature, age, and operating condition of the battery. More detailed battery model can be used to account for the above behaviors if desired [13].

3) Since wind speed, solar radiation and power demand can vary seasonally, more accurate results can be obtained if the simulation study is performed using seasonal data. The approach can also be used to enhance the performance of the system during different seasons. An engineering judgment can then be made (for selecting the system component sizes) based on the results obtained for different seasons.

4) The simulation results presented in this paper are for one set of system components selected based on the actual wind and solar radiation data available at one specific location (in south-central Montana) to supply the power demand of an average house in the northwestern United States. However, the approach can be applied to other locations if and when data is available. Sensitivity studies are needed, using actual wind and solar radiation data at several locations, to bring forth the versatility of the proposed approach. This is the subject of a future study by the authors.

5) Table I gives the component sizes needed to supply the average power demand of a house at the site studied. At the first glance it seems like the proposed (wind + $\mathrm{PV}+$ backup) generation plus the storage battery is too much generation to supply the power demand of a house with a peak demand of about $2 \mathrm{~kW}$. One main reason for this is that the hourly average wind is low at the site 
under study (specially, in the morning hours), as shown in Fig. 4. Therefore, the wind generator puts out a small percentage of its rated power. As a result, bigger component sizes are needed for the generating system. This may not seem economically appealing at a first glance. However, the authors did a thorough cost analysis of the proposed stand-alone hybrid (wind/PV) system for the site under study using the capital cost of the system as well as the annual cost of maintaining it over a 20 -year period using $6 \%$ interest rate [1]. In this reference, the authors used the 1996 Montana Power Company's cost figures and showed that the installation and maintenance cost of the proposed stand-alone system would be economically justified if the load site is more than two miles away from the nearest utility distribution feeder. They compared the total cost of the wind/PV system with that of constructing a power line extension to supply the load with conventional utility power from the nearest utility distribution feeder to the site. It is expected that this cost will be even more justified in the future considering the falling prices of the wind/PV generating system components and increasing utility charges. The cost will also be more justified if the system is installed at a site with a better wind/solar regime.

\section{CONCLUSION}

This paper reported an approach for evaluating the general performance of stand-alone wind/PV generating systems. It is a useful tool for predicting the performance of the such generating systems before they are built. It can also be used to explore the cost versus benefits of increasing or decreasing the size (rating) or the number of each system component.

An electric water heater was used for the dump load to use the excess wind/solar-generated power to pre-heat the water flowing in the main house water heater. Simulation results were presented to predict the performance of a stand-alone wind/PV generating system supplying power to an average house assumed to be located in a rural area in south-central Montana. It was shown that savings in the water heater fuel can be made by pre-heating the cold water entering the main house water heater using an auxiliary electric water heater as the dump load for the wind/PV generating system.

\section{APPENDIX A \\ STORAGE BATTERY INPUT/OUTPUT RELATIONSHIPS}

Here, we obtain the battery voltage as a function of powerflow into or out of the battery.

The capacitance value was calculated for a $24 \mathrm{~V}, 2.1 \mathrm{kWh}$ battery as follows: $E=1 / 2 \mathrm{CV}^{2}, E=2.1 \mathrm{kWh}=7.56 \times 10^{6}$ $\mathrm{J}$, or $C=26250^{\circ} \mathrm{F}$.

At any given time $t, i_{c}(t)=c d v_{c}(t) / d t, i_{s}(t)=v_{c}(t) / R_{s}$, and $i(t)=i_{s}(t)+i_{c}(t)$. Knowing $i(t)$, the battery output voltage can be obtained as $v(t)=\Delta P(t) / i(t)$. During the charging period, $\Delta P=\left(P_{g}-P_{\text {demand }}\right)>0, v(t)=v_{c}(t)+R_{c} \cdot i(t)$, and during the discharging periods $v(t)=v_{c}(t)-R_{d} \cdot i(t)$. The resistance values used in this study are: $R_{s}=25 \mathrm{M} \Omega$, and $R_{c}=R_{d}=1 \mathrm{~m} \Omega$.

\section{APPENDIX B}

NuMERICAL VALUES USED FOR ELECTRIC WATER HEATER PARAMETERS

Incoming water temperature: $40^{\circ} \mathrm{F}$.

Water heater surrounding ambient temperature: $70^{\circ} \mathrm{F}$. Insulation thermal resistance ( $R$ value): 15 (hour- $\mathrm{ft}^{2-}$ $\left.{ }^{\circ} \mathrm{F} / \mathrm{BTU}\right)$.

Specific heat of water: $=0.000293\left[\mathrm{kWh} /\left({ }^{\circ} \mathrm{F}-\mathrm{lb}\right)\right]$

\section{REFERENCES}

[1] W. Kellogg, M. H. Nehrir, G. Venkataramanan, and V. Gerez, "Generation unit sizing and cost analysis for stand-alone wind, photovoltaic, and hybrid wind/PV systems," IEEE Trans. on Energy Conversion, vol. 13, no. 1, Mar. 1998.

[2] R. Chedid and S. Rahman, "Unit sizing and control of hybrid wind-solar power systems," IEEE Trans. on Energy Conversion, vol. 12, no. 1, Mar. 1997.

[3] R. Yokoyama, K. Ito, and Y. Yuasa, "Multiobjective optimal unit sizing hybrid power generation systems utilizing photovoltaic and wind energy," Journal of Solar Energy Engineering, vol. 116, Nov. 1994.

[4] M. H. Nehrir, G. Venkataramanan, V. Gerez, W. D. Kellogg, and C. A. Good, "Matching electric power demand with wind-generated electric power: An intelligent fuzzy logic-based demand side management strategy," in Proceedings, 16th Annual ASME Wind Energy Symposium, Reno, NV, Jan. 6-9, 1997.

[5] M. H. Nehrir, B. J. LaMeres, and V. Gerez, "A customer interactive electric water heater demand-side management strategy using fuzzy logic," in Proceedings, 1999 IEEE PES Winter Meeting, New York, NY, Jan. 31-Feb. 4, 1999.

[6] Z. M. Salameh, M. A. Casacca, and W. A. Lynch, "A mathematical model for lead acid batteries," IEEE Trans. on Energy Conversion, vol. 7, no. 1, Mar. 1992.

[7] Handbook of Batteries, Second ed., D. Linden, Ed., McGraw Hill Inc., New York, NY, 1995.

[8] P. S. Dolan and M. H. Nehrir, "Development of a residential electric water heater model using energy flow analysis techniques," in Proceedings, North American Power Symposium, Reno, NV, Oct. 5, 6, 1992.

[9] P. S. Dolan, M. H. Nehrir, and V. Gerez, "Development of a Monte Carlo based aggregate model for residential electric water heater loads," Electric Power Systems Research, vol. 36, no. 1, 1996.

[10] J. Cahill, K. Ritland, and W. Kelly, Description of Electric Energy Use in Single Family Residences in the Pacific Northwest: 1986-1992. Portland, OR: Office of Energy Resources, Bonneville Power Administration, Dec. 1992.

[11] G. L. Johnson, Wind Energy Systems, NJ: Prentice Hall, 1985.

[12] M. H. Nehrir, G. Venkataramanan, V. Gerez, and B. LaMeres, "Component sizing for stand-alone wind-electric generating systems: Frequency and time span of data needed," in Proceedings, 17th Annual ASME Wind Energy Symposium, Reno, NV, Jan. 11-15, 1998.

[13] S. Waaben, I. Moskowitz, J. Federico, and C. K. Dyer, "Computer modeling of batteries from nonlinear circuit elements," Journal of Electrochemical Society: Electrochemical Science and Technology, vol. 132, no. 6, pp. 1356-1362, June 1985.

M. Hashem Nehrir received the B.S., M.S. and Ph.D. degrees from Oregon State University in 1969, 1971, and 1978 respectively, all in electrical engineering. He has been on the Electrical and Computer Engineering Faculty at Montana State University since 1987, where he is a Full Professor. His primary areas of interest are control and modeling of power systems and electrical machinery, renewable power generation, and fuzzy logic control applications to power systems. Dr. Nehrir is a member of Eta Kappa Nu and Tau Beta Pi honor societies. 
Brock J. LaMeres received his B.S. degree in electrical engineering from Montana State University in December 1998. In 1996 he did an Internship for VeriBest Inc., an EDA development company. During the summer 1998 he did an internship for Micron Technology Inc. He has been with Hewlett Packard Company in Colorado Springs, Colorado since January 1999, where he works in the hardware design group. He received recognition and several scholarships at MSU for his participation and achievements in undergraduate research. His primary areas of interests are digital signal processing, fuzzy logic control, and microprocessor applications. He was the President of the student branch of Eta Kappa Nu honor society at Montana State University (1997-1998). He is a member of Tau Beta Pi, Phi Kappa Phi, and Golden Key honor societies.

Giri Venkataramanan received the B.E. degree from the Government College of Technology, Coimbatore, of the University of Madras, India, the M.S. degree from the California Institute of Technology Pasadena, and the Ph.D. degree from the University of Wisconsin, Madison in 1986, 1987, and 1992, respectively, all in electrical engineering. He joined the Electrical Engineering Department at Montana State University in 1992, where he is currently an Associate Professor His interests include modeling, design and control of power conversion systems and introduction of pragmatism education.
Victor Gerez received the engineering degree from the National University of Mexico and the M.S. and Ph.D. degrees from the University of California, at Berkeley in 1958, 1969, and 1972 respectively, all in electrical engineering. From 1958 to 1969 he was an Electrical Design Engineer for several Mexican companies. In 1973 he became Chairman of the Mechanical-Electrical Engineering Department at the National University of Mexico. In 1977 he became the Director of the power system division in Mexico's Electric Power Research Institute. He joined the Electrical Engineering Department at Montana State University in 1983, where he is a Full Professor; he was department head from 1984 to 1996 